\title{
Laboreal
}

Volume $6 \mathbf{N}^{\circ} 2$ | 2010

Varia

\section{A libertação da mão}

La liberación de la mano

Libération de la main

The liberation of the hand

\section{André Leroi-Gourhan}

Tradutor. João Viana Jorge

\section{(2) OpenEdition}

\section{Journals}

\section{Edição electrónica}

URL: http://journals.openedition.org/laboreal/8861

DOI: 10.4000/laboreal.8861

ISSN: 1646-5237

\section{Editora}

Universidade do Porto

\section{Refêrencia eletrónica}

André Leroi-Gourhan, «A libertação da mão », Laboreal [Online], Volume 6 N²2 | 2010, posto online no dia 01 dezembro 2010, consultado o 24 setembro 2020. URL : http://journals.openedition.org/ laboreal/8861 ; DOI : https://doi.org/10.4000/laboreal.8861

Este documento foi criado de forma automática no dia 24 setembro 2020.

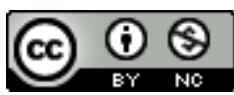

Laboreal está licenciado com uma Licença Creative Commons - Atribuição-NãoComercial 4.0 Internacional. 


\title{
A libertação da mão
}

\author{
La liberación de la mano \\ Libération de la main \\ The liberation of the hand
}

André Leroi-Gourhan

Tradução : João Viana Jorge

\section{REFERÊNCIA}

Artigo original : Leroi-Gourhan, A. (1959). Libération de la main. Problèmes, revue de l'Association des étudiants en médecine de l'Université de Paris, n 32, 1956 (p. 6-9).

1 A oposição entre a mão constantemente disponível do homem e a mão locomotora do quadrúpede constituiu, sob os mais diversos pontos de vista, o objecto da reflexão dos filósofos, dos anatomistas e dos paleontólogos. Apanágio do homo faber, o mais bem organizado instrumento do cérebro de toda a série zoológica, a mão, livre dos seus constrangimentos locomotores, é o símbolo da evolução do homem e, mesmo os trabalhos os mais distantes da metafísica sacrificam involuntariamente ao antropocentrismo ao isolar o técnico e o pensador cujas mãos se tornaram servidoras. Numa perspectiva mais próxima do movimento que anima os seres através do tempo, a tecnicidade, o pensamento, a locomoção e a mão aparecem como que ligados num só fenómeno ao qual o homem dá o significado mas ao qual nenhum membro do mundo animal é completamente estranho.

2 A um nível no qual mundo animal e mundo vegetal se separam de maneira ainda imprecisa, ao nível do ouriço-do-mar e da holotúria (pepino-do-mar), os seres optam entre dois modos de relação com o meio exterior ; uns, imóveis, vêem gravitar à volta deles o universo comestível, esperando que o acaso lhes faça passar uma parte ao alcance do seu orifício bucal : a sua organização permanece a de uma roda ou de uma moita ; os outros comportam-se activamente perante os alimentos, procuram, caçam, escavam : o seu organismo é construído segundo um eixo longitudinal. Presente, logo, 
nos estádios inferiores dos invertebrados, a simetria axial mantém-se como o esquema estrutural exclusivo dos vertebrados. Reunidos na parte anterior, as maxilas, os órgãos da visão e do olfacto, os comandos centrais do sistema nervoso constituem o centro de um campo de relações que os músculos da parte posterior do corpo deslocam através do meio. A cabeça, centro do campo de relações, e o corpo, órgão de locomoção são como que associados um ao outro pela transição do membro anterior. De modo que já nos peixes as funções dos braços são diferentemente partilhadas entre a relação e a propulsão pura. A barbatana natatória peitoral do tubarão é um leme, a do ruivo é um órgão táctil e gustativo. Constatar esta ambiguidade de situações do membro anterior garante o acesso a um dos níveis profundos da história das espécies.

o dispositivo de relação é, à partida, constituído pela caixa craniana que aloja os órgãos frágeis e imóveis e por dois elementos resistentes e móveis : a mandíbula e o braço ; o conjunto localiza-se na extremidade do eixo vertebral que assume a dupla função de vigamento dos elementos motores e de bainha protectora do sistema nervoso autónomo. A passagem da via aquática à vida terráquea em nada modifica este conjunto: os primeiros anfíbios terrestres assemelharam-se a pequenas enguias providas de patas frágeis, mas o seu esqueleto, em particular do membro anterior já é surpreendentemente semelhante, na sua composição, ao dos répteis e dos mamíferos que virão a aparecer com o andar dos tempos. Adquirida esta passagem à vida terráquea, o movimento ascensional dos órgãos de relação esboça-se rapidamente dado que no final da era primária não restam senão duas etapas a ultrapassar : a dos macacos e a do homem (figura 1).

Figura 1

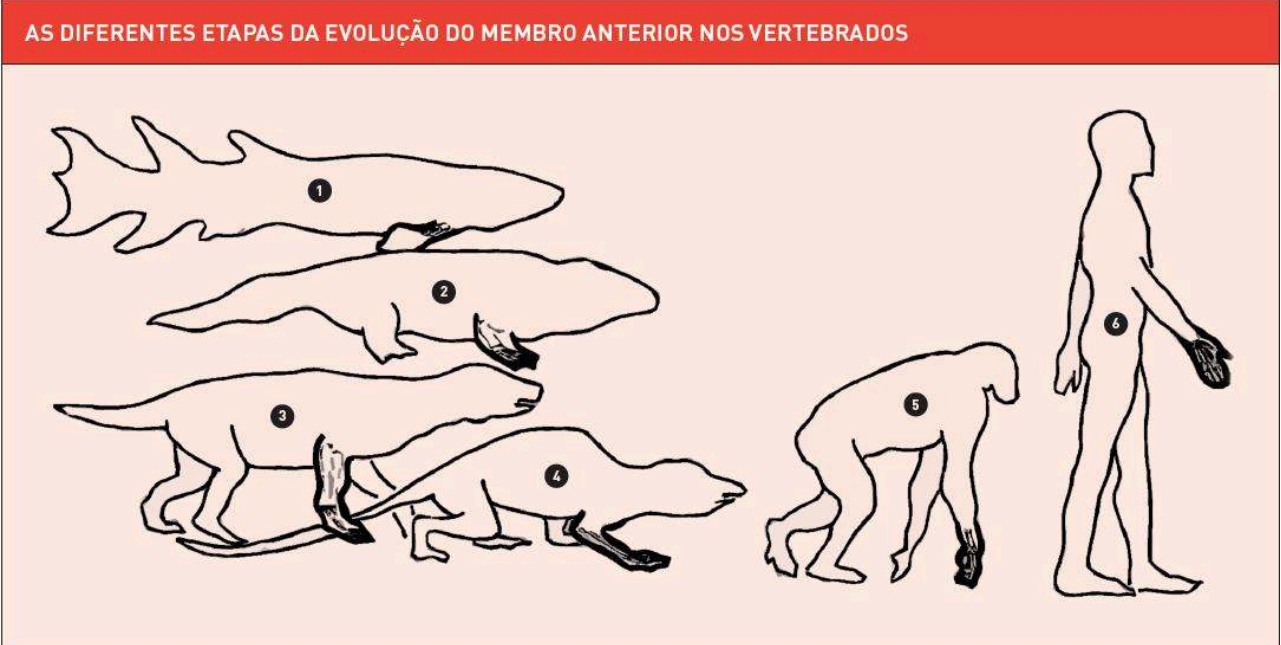

Legenda : As diferentes etapas da evolução do membro anterior nos vertebrados - 1.0 Eusthenopteron, peixe existente há 375 milhões de anos ; 2 . 0 Ichthyostega, anfíbio primitivo ; 3 . 0 Thrinaxodon, antepassado possível dos mamíferos ; 4 . Mamífero primitivo ; 5 . 0 chimpanzé ; 6 . 0 homem

4 A primeira etapa é aquela em que se mantiveram os lagartos actuais : a cabeça tornouse móvel antes de o corpo conseguir arrastar-se pelo solo. Esta libertação da cabeça, que alarga consideravelmente o campo de relação anterior, corresponde a um rearranjo importante : uma parte da coluna vertebral encontra-se integrada no dispositivo de relação à medida que a cintura escapular se desliga do crânio dando lugar, entre cabeça 
e braço ao troço cervical da coluna. Para avaliar a importância das transformações é preciso galgar mais um degrau.

5 Vários milhões de anos antes do aparecimento do primeiro mamífero o corpo liberta-se do contacto com o solo e o réptil apoia-se em quatro membros colunares. A libertação dos constrangimentos da reptação assinala o momento decisivo, o centro de gravidade à volta do qual o mundo vivo gira para mostrar uma nova faceta. Durante o estabelecimento de um novo modelo respiratório, de caixa torácica fechada por um diafragma e accionada pela musculatura costal, o dispositivo de relação proporciona os primeiros exemplos de diferenciação clara dos seus meios técnicos : os dentes que até então eram simples gradeamentos para reter as presas durante a deglutição, diferenciam-se em incisivos, caninos e molares; a mão que não era mais do que um suporte ou um conjunto de ganchos começa a evoluir para funções diferenciadas : o maior problema da evolução passa do plano da preensão dos alimentos ao da autêntica tecnicidade, do de goela em propulsão ao de órgãos úteis suportados pelo focinho e pelos membros anteriores.

Cada grupo zoológico é um mundo simultaneamente fechado e aberto ; são conhecidos peixes ou répteis muito primitivos com dentes ou mãos tecnicamente diferenciadas mas sempre numa gama de possibilidades muito estreita, enquanto que desde que foi alcançada a locomoção quadrúpede, nos próprios répteis da era secundária, o leque de possibilidades alarga-se do exclusivo consumidor de ervas ao carniceiro, do membro de suporte do diplodocus ao utensílio manual para prender e dilacerar do tiranossáurio. A partir deste ponto o anterior campo de relações engloba um duplo campo técnico, o do focinho e o da mão (Figura 2).

Figura 2

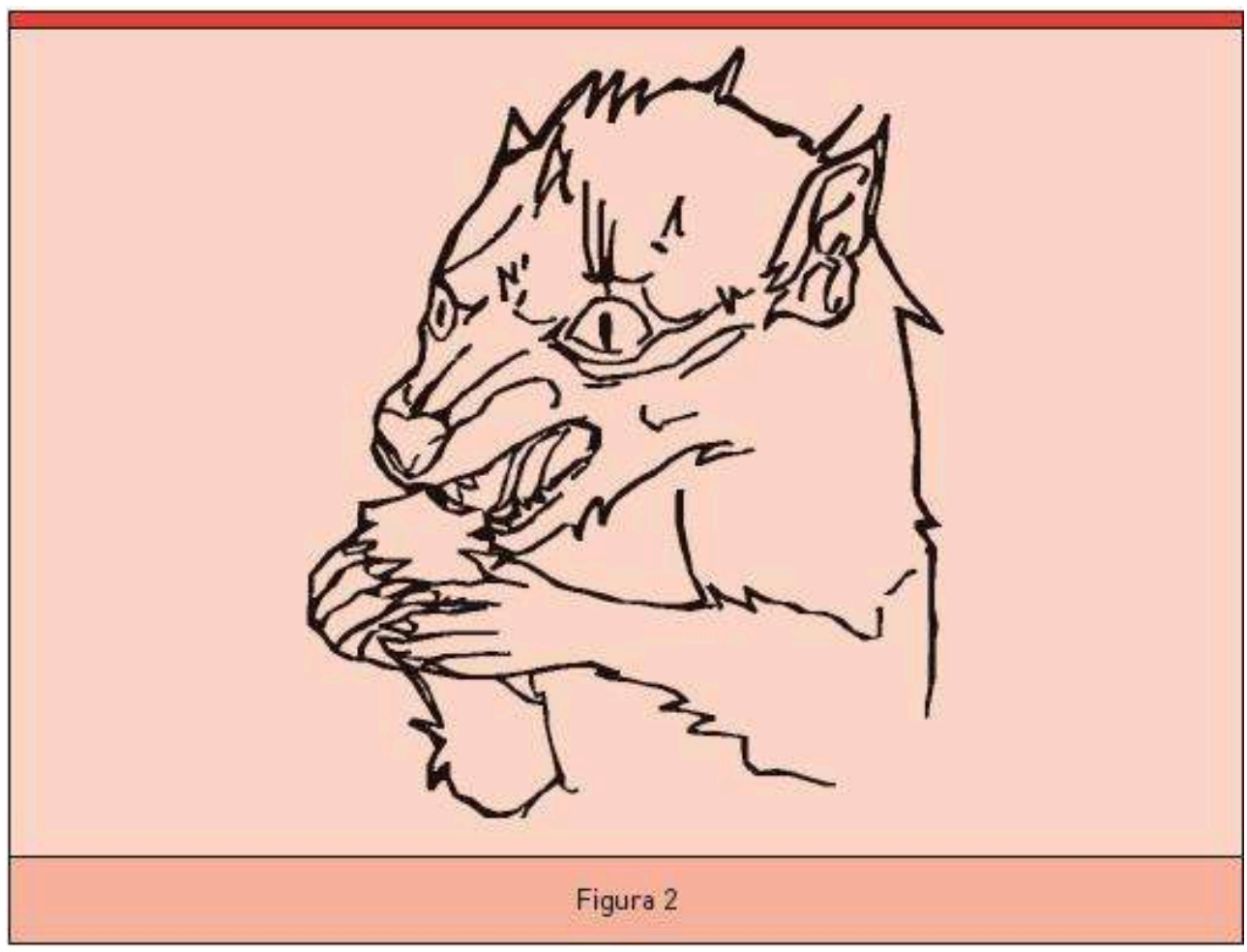


7 Ao longo da história dos mamíferos que começam a desenvolver-se no fim do secundário, assiste-se a um verdadeiro balanceamento proporcional entre o campo técnico facial e o campo técnico manual, como se a relação entre as necessidades e os meios técnicos necessários à sua satisfação se equilibrassem para cada uma das espécies entre os dois pólos do campo anterior.

8 Entre todas as fórmulas, entre os mamíferos, desenha-se uma repartição clara no decurso da era terciária. Os mamíferos marinhos, focas e baleias, iniciam uma adaptação regressiva que os reconduz ao ponto de partida : grade de dentes idênticos e braços-natatórios. Os comedores de vegetais enveredam por outra via. O braço flexível e a mão de cinco dedos herdada dos anfíbios e dos répteis, em vez de se orientarem para a tecnicidade manual organizam-se para a locomoção. As articulações perdem os seus movimentos laterais e a mão deixa progressivamente o campo de relação, abandonando progressivamente os dedos (quatro no porco, três no rinoceronte, dois no boi e um só no cavalo) para permitir a todo o organismo uma velocidade acrescida. Ao nível do cavalo a servidão da mão em função de uma locomoção aperfeiçoada é total. Em contrapartida o campo facial organiza-se, os dentes tornam-se utensílios cada vez mais bem adaptados à preensão dos alimentos, os lábios reúnem todas as possibilidades de percepção táctil e de preensão delicada, a face equipa-se com apêndices técnicos, trombas, cornos, defesas, batentes.

9 A evolução segundo um outro eixo alinha em ordem progressiva os mamíferos que libertam a mão (parcialmente e depois totalmente) dos constrangimentos locomotores. Carnívoros e comedores de coisas tenras e carnudas, os carniceiros, os roedores, os primatas marcam as principais etapas. Como nas precedentes, cada grupo zoológico retoma por sua conta as grandes perspectivas do caminho a percorrer : entre o cão dispondo de mão locomotora e o rato-lavador com mão altamente adaptada às operações técnicas, entre a cobaia e o rato, entre o lémur e o chimpanzé desenha-se encurtado todo o movimento, mas cada série progressiva supera as precedentes.

Os carniceiros iniciam um tipo de postura que os herbívoros ignoram: a postura sentada. À rigidez vertebral e articular da marcha dos herbívoros opõe-se a flexibilidade dos mamíferos superiores : sentados, o leão pode libertar uma das suas mãos para agarrar, o urso é capaz de libertar as duas e o rato-lavador pode coordenar os movimentos em acções assaz complexas. O seu comportamento aproxima-se do dos roedores mais evoluídos (rato, hamster, marmota, esquilo, castor) que passam uma parte importante das suas vidas sentados, ocupados com a manipulação dos alimentos, com os cuidados corporais de se coçarem e pentearem manualmente, com complicadas ocupações técnicas de construção ou de arranjo do seu habitat. Nos roedores evoluídos, os dois campos técnicos, manual e facial, estão quase em equilíbrio, mas o incisivo, instrumento alternadamente alimentar e técnico, desempenha um papel tão constante que a actividade se encontra ainda polarizada no focinho: é preciso chegar aos primatas para assistir à inversão das proporções.

11 Os primatas não constituem um grupo funcional mais homogéneo que os outros por que se neles não se encontram puros quadrúpedes, a distância que separa as formas extremas é considerável. Todo o grupo dos lémures e dos macacos é caracterizado pela vida arborícola; mãos e pés apresentam uma característica que é partilhada por um certo número de répteis e de aves trepadoras : a oponibilidade de certos dedos (neste caso o polegar) ao resto da mão. Esta adaptação é de carácter fundamentalmente locomotor, a oposição do polegar é uma das soluções do problema da locomoção 
arborícola, mas é uma solução privilegiada porque a mão, órgão locomotor, quando fica livre na posição sentada, torna-se um instrumento de preensão extremamente preciso e flexível. Há portanto uma coincidência, nos primatas, entre os constrangimentos da locomoção e as solicitações técnicas, o que arrasta, das formas primitivas às formas superiores, uma polarização sucessivamente mais clara do campo técnico sobre a mão.

Como resposta à importância que a preensão manual adquire assiste-se ao fenómeno inverso que se desenha nos herbívoros: o aparelho dentário cede progressivamente importância. A regressão dos caninos e o encurtamento da face tem uma relação directa com a evolução da extremidade do membro anterior em direcção à forma e uso da mão humana.

13 A regressão do dispositivo dentário é um fenómeno de extrema importância porque está demonstrado que os constrangimentos mecânicos impostos pelas maxilas têm uma relação directa com as possibilidades de expansão da abóbada craniana e com o equilíbrio do crânio no topo da coluna vertebral. Os primatas encontram-se, em consequência, arrastados para uma direcção evolutiva em que o endireitamento do corpo na posição sentada, o uso técnico da mão, a regressão do maciço facial e o desenvolvimento do cérebro se apresentam num estado interactivo favorável. No limite, alcançaram-se as condições pré-humanas.

14 A passagem do quadrúmano mais evoluído ao "bímano" mais fruste não está ainda esclarecida : o pé dos grandes símios não se acomoda à marcha bípede, mas certas formas como o gibão ou o cinocéfalo permitem admitir sem inverosimilhanças, a existência, durante o terciário, de formas menos especializadas do que os antropóides actuais, mais orientadas para a vida nas rochas e nos bosques do que nas árvores, utilizando a mão, no solo, em posição sentada ou de pé, em operações alimentares e sem recorrer senão acidentalmente à locomoção quadrúpede. Estas formas são ainda desconhecidas e as descobertas mais recentes na África do Sul ultrapassam já, com os australopitecos, essa fase. Com efeito os australopitecos são bípedes; estão ainda próximos dos símios pelo tamanho do crânio mas o seu desenvolvimento está completo [...] e a redução considerável dos seus dentes anteriores permite pensar que a polarização técnica no campo manual é de um grau comparável à que se encontra em todos os humanos fósseis e actuais. A ideia do homem fóssil, meio inclinado para a terra pelo peso do focinho e dos seus longos braços perdeu significado já há anos e apercebemo-nos de que se a organização cerebral do homem actual é uma característica de aquisição relativamente tardia, o endireitamento da estatura e a libertação da mão são, pelo contrário, os primeiros critérios de humanização visíveis : os australopitecos são homens pela sua postura e pela mão bem antes de toda a humanidade baseada em critérios morais e intelectuais.

A partir desse ponto deixa de haver grandes transformações expectáveis para a mão, o instrumento existe e os principais eventos vão incidir sobre o arranjo dos centros nervosos que a comandam. Com a actividade técnica polarizada no campo manual, a face prossegue na sua regressão o que arrasta uma libertação cada vez mais completa da abóbada craniana. Esta libertação mecânica começa na região parietal (símios superiores) depois atinge o occipital (australopitecos, pitecantropus, néandertalenses) mas o desbloqueio do frontal aparece tardiamente (homens de Cro-Magnon). A libertação do segmento parietal traduz-se por uma expansão progressiva dos territórios cerebrais de um lado e do outro do sulco de Rolando, quer dizer pelo desenvolvimento das áreas corticais de integração e de associação motoras. A integração motora está em 
relação directa com a tecnicidade e a topografia cortical mostra, nos símios, a importância primordial e sensivelmente equivalente das fibras respeitantes ao membro anterior (em particular ao polegar) e das fibras da face (em particular lábios e língua).

Quando se passa do símio ao homem as áreas corticais motoras expandem-se e ganham territórios e associações que avançam para a região frontal ; ora, apesar da regressão considerável da face a importância cortical dos campos manual e facial mantém-se sensivelmente equivalentes. Este facto muito importante mostra um último traço da evolução humana, impossível de evidenciar pela paleontologia; logo que se desenvolve de maneira quase exclusiva a tecnicidade manual uma nova forma de actividade toma progressivamente posse do campo facial : a mímica e a linguagem. Não se processa qualquer rotura porque os movimentos dos lábios e da língua deslizam simplesmente das operações alimentares para a modulação dos sons com os mesmos órgãos e as mesmas áreas motrizes ligadas às duas formas de actividade.

17 Esta relação entre a tecnicidade manual e a linguagem implicada de certo modo por uma evolução que se pode seguir desde os primeiros vertebrados é seguramente um dos aspectos mais satisfatórios da paleontologia e da psicologia porque restituem as ligações profundas entre o gesto e a palavra, entre o pensamento exprimível e a actividade criadora da mão. 